\title{
LIGAND FIELD ANALYSIS OF METAL-OXYGEN INTERACTIONS-I. TRIS(OXALATO)COBALTATE(III)
}

\author{
SNEŽANA ZARIČ and S. R. NIKETIĆ ${ }^{*} \dagger$ \\ Department of Chemistry, Faculty of Science, University of Belgrade, Studentski trg 16, \\ P.O. Box 550, YU-11001 Belgrade, Yugoslavia
}

(Received 10 July 1991 ; accepted 1 August 1991)

\begin{abstract}
Ligand field analysis of $\left[\mathrm{Co}(\mathrm{ox})_{3}\right]^{3-}$ has been performed using the angular overlap model (AOM) approach. The metal-oxygen interactions were treated as locally anisotropic. Experimental spectra were well reproduced by the calculations in which the Trees' correction was included. The effect of geometrical distortions on the calculated energies of ligand field states has been investigated.
\end{abstract}

Our previous ${ }^{1,2}$ study of tris(aminocarboxylato) cobalt(III) complexes revealed that the differences in the electronic structure between complexes with five-membered glycinato and six-membered $\beta$-alaninato chelate rings are a consequence of different torsional angles around $\mathrm{M}-\mathrm{O}$ bonds (due to the non-planarity of $\beta$-Ala rings) rather than of different chelate $(\mathrm{N}-\mathrm{M}-\mathrm{O})$ angles. The observation led us to propose a hypothesis about the anisotropy of the $\mathrm{M}-\mathrm{O}$ interaction involving the carboxylato oxygen ligator. This model offered, therefore, the possibility to relate the conformation of a chelate ring to the electronic structure of the coordination complex.

To investigate further this relationship in structures with flexible metal chelate rings, we sought for other examples of chelate complexes containing coordinated carboxylato oxygen(s), in which the influence of chelate ring conformation is expected to be observable via the anisotropy of $\mathrm{M}-\mathrm{O}$ interactions.

Tris(oxalato) complexes chosen for this study ${ }^{3}$ do not offer wide structural variations with respect to the ring conformation. Nevertheless, as shown in this paper on $\left[\mathrm{Co}(\mathrm{ox})_{3}\right]$ structures, and in the next paper on $\left[\mathrm{Cr}(\mathrm{ox})_{3}\right]$ structures, small structural deformations of the $\mathbf{M}(\mathrm{ox})_{3}$ skeleton are capable of producing significant changes in calculated energies of the ligand field states.

* Author to whom correspondence should be addressed. †E-mail address:〈xpmfh01@yubgss21.bitnet〉.
Another reason for our choice is that tris(oxalato) complexes offer a possibility to investigate the extent of transferability of ligand field parameters across the series of chromophores $\mathrm{MN}_{6-3 n}$ $\mathrm{O}_{3 n}$ for $n=0,1,2$. In the previous study ${ }^{2}$ on tris(aminocarboxylato) complexes (chromophore $\mathrm{MN}_{3} \mathrm{O}_{3}$ ) we used the AOM parameters for nitrogen optimized on the $\mathrm{MN}_{6}$ chromophore. Here we wanted to determine whether the AOM parameters for oxygen are transferable to the $\mathrm{MO}_{6}$ chromophore as well.

\section{COMPUTATIONAL METHODS}

This ligand field analysis is based on the angular overlap model (AOM) approach. ${ }^{4-7}$ Here we shall briefly examine geometry relationships for tris(oxalato) structures which are of importance for the AOM analysis. Then we shall outline some extensions of the AOM model used in this as well as in the following ${ }^{8}$ work.

\section{Trigonal dihedral geometry definition}

The overall coordination geometry of a regular $\left(D_{3}\right)$ trigonal dihedral tris(bidentate) structure is completely defined by any two of the three geometrical descriptors : chelate angle $(\alpha)$, tilt angle $(\theta)$ or twist angle $(\omega)$ (see e.g. Fig. 2 in Ref. 2). In the so-called trigonal orientation (i.e. $z$-axis coinciding with the molecular $C_{3}$ axis, and the $x$-axis bisecting the chelate angle, $\alpha$ ) the geometry of the metal coordination sphere may be completely defined by, e.g. 


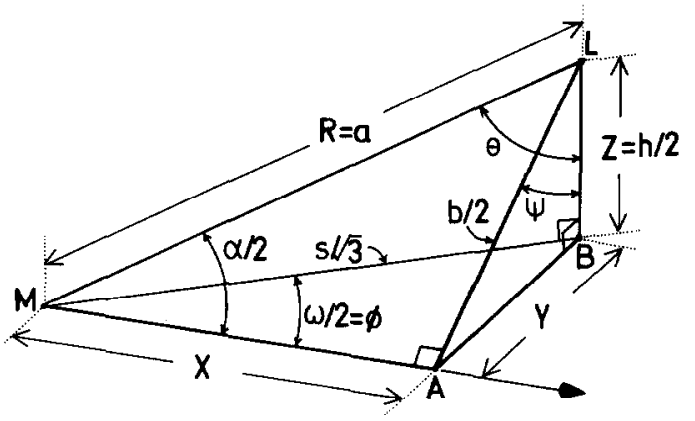

Fig. 1. Rectangular tetrahedron defined by the position of one of the ligator atoms $(L)$ in a trigonally oriented $D_{3}$ tris(bidentate) structure showing the relationships between various geometry descriptors. Angles $\alpha, \theta$ and $\omega$ are defined in the text. Line L-A is equal to a half of the bite distance $L-L$, and line $L-B$ is a hall of the octahedron height $(h) . \mathrm{M}-\mathrm{B}$ is likewise related to the length of the octahedron side ( $s$ ) through a factor of $\sqrt{3}$. Angle $\psi$ shown on this figure is the pitch angle (octahedral vaiue $=35.5^{\circ}$ ) and not the $\psi($ AOM $)$ (octahedrai value $=45^{\circ}$ )

the two spherical polar coordinates of one of the ligators on a sphere the radius of which corresponds to the unit $\mathrm{M}-\mathrm{L}$ distance. Several workers ${ }^{9-16}$ have commented on tarious relations between $x, 8$ and $\omega$ angies or other (simple or derived) geometry cescripiors and jigaror (either spherical polar or Cartesian) coordinates. However, it is possible to cerive ais inese and many oiner rebaionsmips between geometry descriptors of a trigonal dihedral tris(bidentate) structure by considering the trigconometry of a reciangular ietranedron (Fig. 3) cốnneb' Dy ine, position of one of ine'iggaror aroms in a trigonally oriented structure.

Any regular (i.e. $D_{3}$ or $C_{3}$ ) tris(bidentate) structure can easily be brought into a trigonal orientation and compared to other similar structures. The situation is less straightforward for the structures which lack any symmetry. Indeed, all reported crystal structures of the $M(\mathrm{ox})_{3}$ ion, except one (see below), are unsymmetrical. Therefore, any attempt to define their structural deformations must assume some kind of averaging of the geometrical descriptors. There are essentially two methoas tôr aỏing this.

In cases of small deviations from $C_{3}$ symmetry, it is possible to define average values of chelate and other revarat oonb angles ${ }^{12,13}$ and to berive caverage twist andes 303 irrespective of mojectiar conentaion. Ainernaiveejy, in is possibie to fno ine best trigonal orientation ${ }^{10,11}$ of a low symmetry structure which gives an $\sigma$ and a pair of $\theta$ angles ("upper" and "lower") for each chelate ring. We prefer the latter method because it retains the orig- inal structural information and, at the same time, allows for various levels of averaging if and when necessary.

\section{Trigonal deformations in $\mathrm{M}(\mathrm{ox})_{3}$ structures}

Five-membered M(oxalato) chelate rings are either nearly planar or deformed in an irregular way. Accordingly, in assessing the effects of structural variations in $\mathbf{M}(\mathrm{ox})_{3}$ structures on the results of AOM analysis, it is equally important to consider the modes of departure from the regular octahedral symmetry of the coordination polyhedron. For that reason we have analysed geometries of $\mathrm{M}(\mathrm{ox})_{3}$ ions as reported in published crystal structure determinations.

From the $\mathrm{CSD}^{17}$ we have extracted data on 30 crystal structure determinations of $\mathrm{M}(\mathrm{Ox})_{3}$ ions. Except in one case (PNIOCO, space group $P 2,3$ allowing for $C_{3}$ symmetry of the complex anion), all the structures belong to space groups which permit at most $C_{1}$ and/or $C_{2}$ site symmetries, but $\mathrm{M}(\mathrm{ox})_{3}$ ions in all of them were of $C_{1}$ symmetry! In order to find the values of $\theta$ and $\omega$ for these $M(o x)_{3}$ structures we have adopted the following procedure. Mid-points between ligator atoms belonging to the same chelate rings (three points) and thase betwisen digatons an the apposice trigonal faces on adjaent chelate rings (another three points) were located. Eulerian rotations were then applied iteratively, keeping the metal atom in the vrigo, so that the som of spuares of the tisplacements of all the six points from the $x y$-plane is minimized. In this orientation the axis perpenticulat to the xy-plane and passing though the

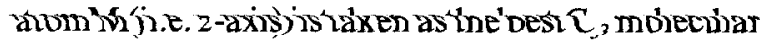
axis. Angles $\theta$ and $\omega$ for each chelate ring were calculated with respect to this $C_{3}$ axis. Subsequent smoothing of the structure may be performed in two steps: by averaging the $\omega$ angles to get $C_{3}$ symmetry, and by averaging the $\theta$ angles to get $D_{3}$ symmetry. This method may be regarded as an elaboration of the twist angle definition $\phi^{61}$ of Flandera and Lingafelter. ${ }^{11}$ It is numerically stable and yields the smallest variation in $\omega$ and $\theta$ angles among the chelate rings.

Âmong many possib̉e divariàce reibutionsilips of the geometrical descriptors of tris(bidentate) structures we have found that a plot of $\omega$ vs $\theta$ yields the most Hastrative overview of ine Maxis befor-

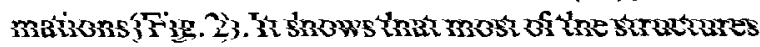

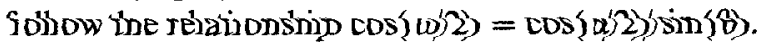
Furthermore, metal ions of similar ionic radii have approximately similar $\alpha$ angles. Therefore, the points in the $\theta-\omega$ plot belonging to the same metal atom or those with similar ionic radii, follow the 


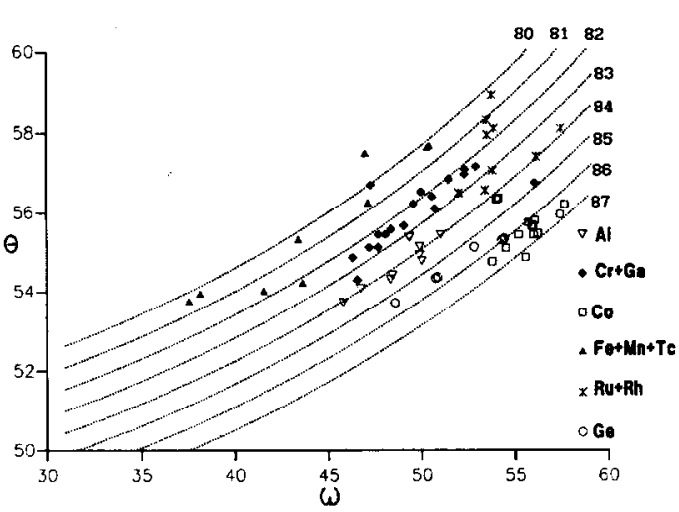

Fig. 2. X-ray structures of $\left[\mathrm{M}(\mathrm{ox})_{3}\right]^{3-}$ ions on the $\theta-\omega$ plot showing that most of the structures approximately follow the relationship $\cos (\omega / 2)=\cos (\alpha / 2) / \sin (\theta)$, and that metal ions of similar ionic radii have approximately similar $\alpha$ angles. The dotted lines correspond to constant values of $\alpha$, indicated in the upper right corner of the graph. All data extracted from CSD ${ }^{17}$ are shown. ${ }^{18}$

$\alpha=$ const. lines (shown as dotted lines in the background on Fig. 2). A full account of the analysis of all $30 \mathrm{M}(\mathrm{ox})_{3}$ structures is available elsewhere. ${ }^{18}$ Here we give only a summary of the structures of five $\left[\mathrm{Co}(\mathrm{ox})_{3}\right]$ complexes (Table 1).

\section{Definition and specification of $\psi$ angles}

The AOM model which takes into account the anisotropy of an $\mathrm{M}-\mathrm{L}$ bond requires the specification of the $\psi$ angle ${ }^{5}$ in addition to the spherical polar angles which define the position of $L$ on a unit sphere. The angle $\psi$ is related to the torsional angle at the $\mathrm{M}-\mathrm{L}$ bond. However, while the torsional angle is invariant with respect to molecular orientations, the $\psi$ angle depends also on the spherical polar coordinates of the ligator $\mathrm{L}$.

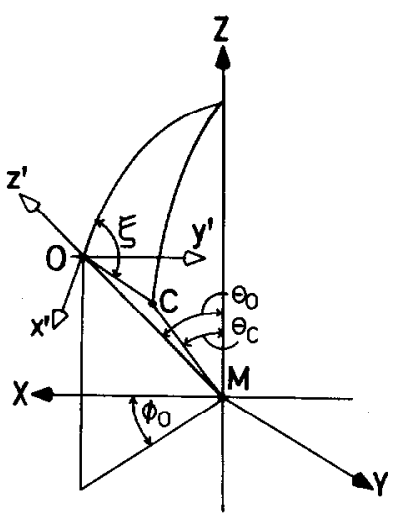

Fig. 3. The spherical trigonometry relationships of the triangle defined by projecting the positions of the oxygen ligator, $\mathrm{O}$, and the neighbouring carbonyl carbon, $\mathrm{C}$, onto the unit sphere around the metal atom. Spherical angle $\xi$ is subtended by the $\mathrm{O}-\mathrm{C}$ line and the $x$-axis of the local coordinate system on the oxygen ligator.

Therefore, $\psi(\mathrm{AOM})=\operatorname{abs}(\pi / 2-\xi)$.

One way to evaluate the angle $\psi$ is to locate the coordinates of a ligand atom directly connected to the ligator. In the present case it is the carbonyl carbon, $\mathrm{C}_{k}$. Atoms $\mathrm{M}, \mathrm{O}$ and $\mathrm{C}_{k}$ define a nodal plane for the $\pi$-type orbital on the oxygen ligator. The angle between this plane and the $x z$-plane of the local coordinate system on $O, \xi$, can be defined on the basis of spherical trigonometry relationships of the triangle defined by projecting the positions of $\mathrm{O}$ and $\mathrm{C}_{k}$ onto the unit sphere around the metal atom (see Fig. 3):

$$
\begin{array}{r}
\cos (\psi(\mathrm{AOM}))=\cos (\theta) \times \sqrt{ }\{[\cos 2(\theta)+\cos 2(\alpha / 2) \\
\times \tan 2(\omega / 2)][1+\tan 2(\omega / 2)]\} .
\end{array}
$$

The angle $\psi(\mathrm{AOM})$ has a value of $45^{\circ}$ for the $O_{h}$ symmetry. It should be distinguished from the pitch

Table 1. Selected structural data on $\left[\mathrm{Co}(\mathrm{ox})_{3}\right]^{3-}$ complexes

\begin{tabular}{lccccccc}
\hline CSD & Space & \multicolumn{3}{c}{} & \multicolumn{3}{c}{ Average values } \\
Refcode $^{a}$ & group & \multicolumn{2}{c}{ Chelate angle $(\alpha)$} & $\alpha$ & $\theta$ & $\omega$ \\
\hline DAZVUV & $C 2 / c$ & 86.072 & 86.750 & 86.328 & 86.38 & 55.81 & 56.36 \\
DAZWEG & $P 3_{1} 2_{1}$ & 86.478 & 86.525 & 86.678 & 86.56 & 55.48 & 55.81 \\
PNIOCO & $P 2_{1} 3$ & 84.269 & 84.269 & 84.269 & 84.27 & 56.36 & 54.08 \\
QQQCMAa & $P-1$ & 86.768 & 86.304 & 86.368 & 86.48 & 55.42 & 55.55 \\
QQQCMAb & $P-1$ & 86.202 & 86.235 & 87.299 & 86.58 & 55.38 & 55.61 \\
\hline
\end{tabular}

${ }^{a}$ Refcodes :

DAZVUV-monoclinic $\mathrm{K}_{3}\left[\mathrm{Co}(\mathrm{ox})_{3}\right] \cdot 2 \mathrm{H}_{2} \mathrm{O} .{ }^{43}$

DAZWEG- $\Lambda-\mathrm{K}_{3}\left[\mathrm{Co}(\mathrm{ox})_{3}\right] \cdot 2 \mathrm{H}_{2} \mathrm{O} .^{43}$

$\mathrm{PNIOCO}-\mathrm{K}\left[\mathrm{Ni}(o \text {-phen })_{3}\right]\left[\mathrm{Co}(\mathrm{ox})_{3}\right] \cdot 2 \mathrm{H}_{2} \mathrm{O}^{40}$

QQQCMAa-rac-K ${ }_{3}\left[\mathrm{Co}(\mathrm{ox})_{3}\right] \cdot \mathrm{H}_{2} \mathrm{O}$ (Struct. A) ${ }^{43}$

$\mathrm{QQQCMAb}-\mathrm{rac}-\mathrm{K}_{3}\left[\mathrm{Co}(\mathrm{ox})_{3}\right] \cdot \mathrm{H}_{2} \mathrm{O}$ (Struct. B). ${ }^{43}$ 
(or tilt) angle, $\psi^{19,20}\left(O_{h}\right.$ value $\left.=35.5^{\circ}\right)$, which is related to the angles $\theta$ and $\alpha$ (or $\omega$ ) in the trigonal orientation of an idealized $\left(D_{3}\right)$ tris(bidentate) geometry (as shown in Fig. 1):

$$
\begin{aligned}
\psi=\pi / 2-\operatorname{arcos}[\cos (\theta) / \sin (\alpha / 2)] \\
=\pi / 2-\arctan [\tan (\theta) \times \sin (\omega / 2)] .
\end{aligned}
$$

The latter expression or variants thereof have been sometimes imprecisely cited in connection with the definition of $\psi(\mathrm{AOM}){ }^{14}$

\section{Computational model for the AOM analysis}

The basic computational method for AOM analysis used in this work has been described. ${ }^{2}$ In addition, for the purpose of the present study, we have adopted two extensions to the AOM procedure. They are related to the Trees' correction, and to the explicit treatment of the second coordination sphere. The former is applied both for cobalt(III) and chromium(III) complexes, and the latter only in the case of $\left[\mathrm{Cr}(\mathrm{ox})_{3}\right]^{3-}$ in a crystal environment.

It has been repeatedly demonstrated ${ }^{21-24}$ that the so-called Trees' correction $^{25-28}$ affects the calculated energies both for the free and for coordinated transition metal ions, so that the agreement between calculated and experimental energies becomes improved. form :

Trees' correction is introduced in the following

$$
\begin{aligned}
\langle\alpha \mathrm{SLJM}| & \mathrm{H}(\text { Trees })\left|\alpha^{\prime} \mathrm{S}^{\prime} \mathrm{L}^{\prime} \mathrm{J}^{\prime} \mathrm{M}^{\prime}\right\rangle \\
=\delta\left(\mathrm{S}, \mathrm{S}^{\prime}\right) \delta\left(\mathrm{L}, \mathrm{L}^{\prime}\right) \delta\left(\mathrm{J}, \mathrm{J}^{\prime}\right) \delta\left(\mathrm{M}, \mathrm{M}^{\prime}\right) & \\
\times & \times\{[\mathrm{L}(\mathrm{L}+1)-6 n] \alpha+\beta \mathrm{Q}\} ;
\end{aligned}
$$

where $\alpha$ and $\beta$ are the empirical parameters and $\mathrm{Q}$ the total seniority operator. ${ }^{28}$ For transition metals treated in this study the contribution involving parameter $\beta$ is negligible. $\alpha$ is treated as an empirically adjustable parameter ${ }^{23,29,30}$ with a value ranging from 20 to $110 \mathrm{~cm}^{-1}$.

The other extension of the AOM analysis is related to the inclusion of atoms of the second coordination sphere. Careful inspection of crystal structures of different $\mathrm{M}(\mathrm{ox})_{3}$ ions shows that some counter-ions or polar molecules may influence the crystal field around the central transition metal atom. This influence may be two-fold. Counter-ions may interact with ligand atoms causing small steric and/or electronic deformations which are reflected onto $\mathrm{M}-\mathrm{L}$ interactions. Furthermore, in some $M(o x)_{3}$ structures, there are counter-ions which are located close to the $C_{3}$ (or pseudo- $C_{3}$ ) molecular axis at short distances from the atom $\mathbf{M}$, and thus may have a direct effect on it.

We have treated selceted counter-ions from the outer coordination sphere in the same way as ligator atoms. Their positions (in spherical polar coordinates with respect to the global coordinate system of $M$ ) were determined from the crystallographic data. Their influence on $M$ is small, therefore, only $e_{\sigma}$ parameters are retained. Their magnitudes are roughly estimated on the basis of the well-known relationships between AOM and crystal-field parameters. ${ }^{31-33}$

\section{RESULTS AND DISCUSSION}

\section{Best-fit ligand field parameters}

The basis for the ligand field analysis of tris (oxalato)cobaltate(III) ion was the structural data on five complexes retrieved from the Cambridge Structural Database ${ }^{17}$ (Table 1) and optical spectra. The latter are room temperature solution spectra which provide positions of the low-lying singlet bands ${ }^{34-36}$ and, in one case, ${ }^{37}$ of the first triplet transition. Single crystal spectra ${ }^{38}$ correspond to $\left[\mathrm{Co}(\mathrm{ox})_{3}\right]$ doped in $\mathrm{NaMg}\left[\mathrm{Al}(\mathrm{ox})_{3}\right] \cdot 9 \mathrm{H}_{2} \mathrm{O}$, the crystal structure of which is not known.

For the optimization of crystal field parameters the recent spectral data ${ }^{39}$ for singlet transitions, and reported ${ }^{37}$ triplet transitions, were used. The geometrical model was, therefore, the $C_{3}$ average structure derived from four out of five crystal structure geometries. The average values of descriptors were : $\alpha=86.5, \theta=55.52$ and $\omega=55.83$ degrees. The structure of $\mathrm{K}\left[\mathrm{Ni}(o \text {-phen })_{3}\right]\left[\mathrm{Co}(\mathrm{ox})_{3}\right] \cdot 2 \mathrm{H}_{2} \mathrm{O}^{40}$ was omitted since it deviated from all the other structures for more than $3(\sigma)$ in most of the structural parameters relevant to this study.

The scarcity of spectroscopic data for $\left[\mathrm{Co}(\mathrm{ox})_{3}\right]^{3-}$ limits the number of parameters that could be optimized simultaneously in an AOM calculation. Since our intention was to investigate the transferability of AOM parameters for oxygen, we chose to fix $e_{\sigma}$ and $e_{\pi}$ parameters for the carboxylate oxygen at the values optimized previously ${ }^{2}$ on tris(aminocarboxylato)cobalt(III) complexes. The spin-orbit coupling constant was likewise taken over from the previous $^{2}$ study as an upper limit for cobalt(III) suggested by Wilson and Solomon. ${ }^{41}$ Inter-electron repulsion parameters $F_{2}$ and $F_{4}$ were optimized to fit the singlet and triplet spectra in the following way. The baricentre of the $A_{2}$ and $E_{\mathrm{a}}$ trigonal components was fitted to the position of the first singlet " $d-d$ " band, and the $E_{\mathrm{b}}$ component alone to the second singlet " $d-d$ " band. However, it was not possible to reproduce the experimentally 
Table 2. Results of ligand field analysis on $\left[\mathrm{Co}(\mathrm{ox})_{3}\right]^{3-}$

\begin{tabular}{ccc}
\hline Level & Exptl $\left(\mathrm{cm}^{-1}\right)$ & Calc. $^{a}\left(\mathrm{~cm}^{-1}\right)$ \\
\hline${ }^{3} T_{1 g}$ & $8300^{b}$ & 8760 \\
${ }^{3} T_{2 g}$ & $12,700^{b}$ & 12,180 \\
${ }^{1} T_{1 g}$ & $16,610^{c}$ & $16,600^{d}$ \\
${ }^{1} T_{2 g}$ & $23,750^{c}$ & $23,740^{e}$ \\
\hline
\end{tabular}

${ }^{a} F_{2}=1130 \mathrm{~cm}^{-1}, F_{4}=107 \mathrm{~cm}^{-1}, \alpha($ Trees $)=11 \mathrm{~cm}^{-1}$, $\zeta=600 \mathrm{~cm}^{-1}, e(\sigma)=7400 \mathrm{~cm}^{-1}, e(\pi \mathrm{c})=1700 \mathrm{~cm}^{-1}$ and $e(\pi \mathrm{s})=0$.

${ }^{b}$ Ref. 37.

${ }^{c}$ Ref. 39.

${ }^{d}$ Baricentre of $A_{2}\left(16,480 \mathrm{~cm}^{-1}\right)$ and $E_{\mathrm{a}}\left(16,670 \mathrm{~cm}^{-1}\right)$.

${ }^{e} E_{\mathrm{b}}$ component. The ${ }^{1} A_{1}$ component is calculated at $23,830 \mathrm{~cm}^{-1}$.

observed ${ }^{3} T_{1 g}$ transition. Substantial improvement was achieved by inclusion of the Trees' parameter $\alpha$ in the optimization simultaneously with $F_{2}$ and $F_{4}$. The best parameter set is shown in Table 2.

The resultant Trees' parameter is rather small compared to the value reported ${ }^{42}$ for the free cobalt(III) ion $\left(70 \mathrm{~cm}^{-1}\right)$ although it is expected to be reduced. ${ }^{22}$

\section{Effects of structural deformations}

With the optimized parameters we have next studied deformations of the $\mathbf{M}(\mathrm{ox})_{3}$ structures.
There are essentially two sources for structural variations. First, they are trigonal deformations of the coordination polyhedron, characterized by deviations of global geometry descriptors $(\alpha, \theta$ and $\omega)$ from their regular trigonal dihedral $\left(D_{3}\right)$ values, both with and without retention of the $C_{3}$ axis. Second, deformations may be due to various departures from planarity of the five-membered oxalato metal chelate rings.

\section{Deformations of the coordination polyhedron}

Trigonal elongations or compressions are characteristic deformations of tris(bidentate) structures. Since $\alpha, \theta$ and $\omega$ angles are not independent, changes in, e.g. $\alpha$ are accompanied by simultaneous changes in either $\theta$ or $\omega$ angles.

Simulation of deformations of $\alpha$ on a model structure can, therefore, be effected either at $\theta=$ const. or at $\omega=$ const. In both cases an inversion in the order of trigonal components (A and E) of the ${ }^{1} T_{1 g}$ and ${ }^{1} T_{2 g}$ states takes place at $\alpha=90^{\circ}$. However, the order is opposite in the cases of $\theta=$ const. and $(1)=$ const. These results are shown in Fig. 4 .

The order of trigonal components calculated for the average crystal structure of $C_{3}$ symmetry is $A_{2}<E_{\mathrm{a}}<E_{\mathrm{b}}<A_{1}$. Since the value for $\theta$ in this structure is close to octahedral $\left[\theta\left(O_{h}\right)=54.7^{\circ}\right]$, the order of trigonal components of ${ }^{1} T_{1 g}$ is $A_{2}<E_{\mathrm{a}}$, as predicted by the model structure with $\theta=$ const.
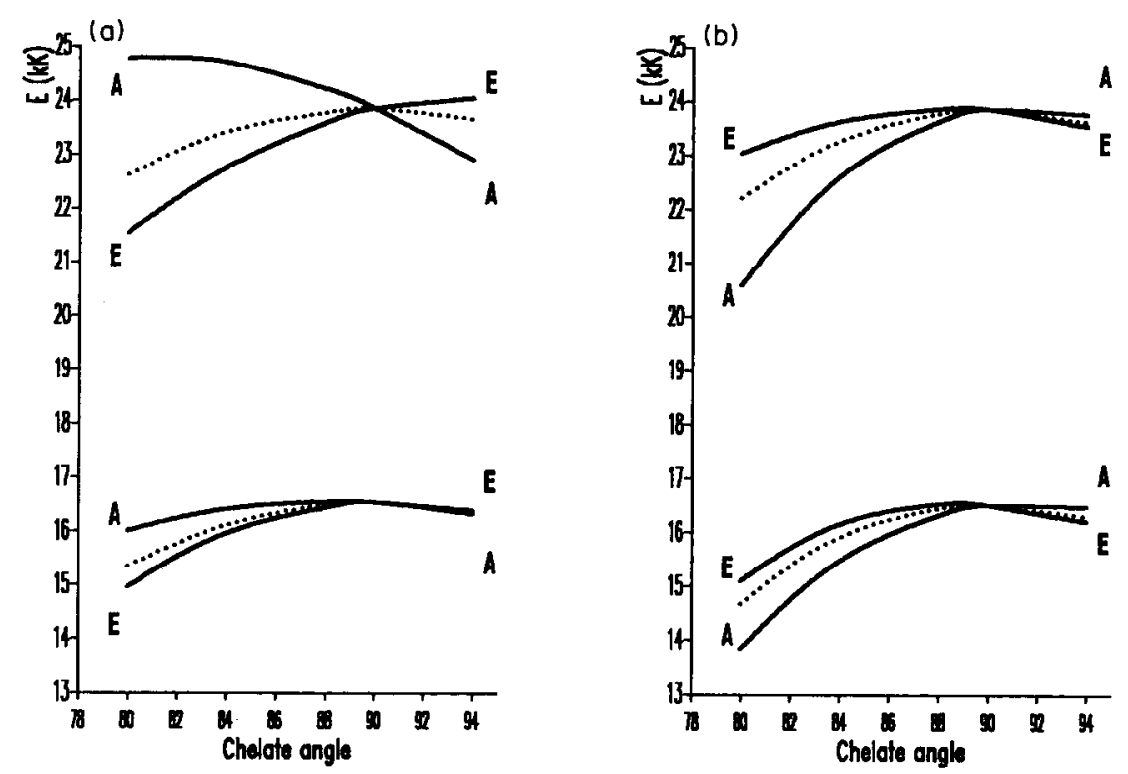

Fig. 4. The influence of trigonal deformations on the positions and splittings of singlets transitions. (a) Simultaneous change of $\alpha$ and $\theta$ at $\omega=60^{\circ}$. (b) Simultaneous change of $\alpha$ and $\omega$ at $\theta=54.74^{\circ}$. Baricentres are shown as dotted lines. For both diagrams the best-fit parameter set was used: $F_{2}=1123 \mathrm{~cm}^{-1}, F_{4}=108 \mathrm{~cm}^{-1}, \zeta=600 \mathrm{~cm}^{-1}, \alpha($ Trees $)=11 \mathrm{~cm}^{-1}, e(\sigma)=7400 \mathrm{~cm}^{-1}$ and

$$
e(\pi \mathrm{c})=1700 \mathrm{~cm}^{-1} \text {. }
$$


Table 3. Results of ligand field analysis ${ }^{a}$ on X-ray structures ${ }^{b}$ of $\left[\mathrm{Co}(\mathrm{ox})_{3}\right]$ complexes

\begin{tabular}{|c|c|c|c|c|c|c|}
\hline \multirow{2}{*}{$\begin{array}{l}\text { Level } \\
\text { in } O_{h}\end{array}$} & \multicolumn{5}{|c|}{ Crystal structures } & \multirow{2}{*}{$\begin{array}{l}\text { Average } \\
\text { struct. }^{c}\end{array}$} \\
\hline & PNIOCO & QQQCMAa & QQQCMAb & DAZWEG & DAZVUV & \\
\hline \multirow{2}{*}{${ }^{\mathrm{I}} T_{1 g}$} & $16,120 E_{\mathrm{a}}$ & $16,370^{d}$ & & $16,380^{d}$ & $16,180 E_{\mathrm{a}}$ & $16,480 A_{2}$ \\
\hline & $16,450 A_{2}$ & & $16,550 \mathrm{~A}_{2}$ & & $16,760 A_{2}$ & $16,660 E_{\mathrm{a}}$ \\
\hline \multirow[t]{2}{*}{${ }^{1} T_{2 g}$} & $23,260 E_{b}$ & $23,360 A_{1}$ & $23,720^{d}$ & $23,420 A_{1}$ & $23,240 A_{1}$ & $23,750 E_{\mathrm{b}}$ \\
\hline & $24,140 A_{1}$ & $23,920 E_{\mathrm{b}}$ & & $23,870 E_{\mathrm{b}}$ & $23,990 E_{\mathrm{b}}$ & $23,830 A_{1}$ \\
\hline
\end{tabular}

${ }^{a}$ Best-fit parameter set from Table 2.

${ }^{b}$ For Refcodes see Table 1.

${ }^{c}$ Average of all crystal structures (except PNIOCO) with imposed $C_{3}$ symmetry axis.

${ }^{d}$ Baricentre (large mixing of $A$ and $E$ states).

The order of trigonal components for ${ }^{1} T_{2 g}$ is more susceptible to the changes of the angle $\theta$, and is difficult to predict when both $\omega$ and $\theta$ are distorted.

The results of calculations on the individual crystal structures are presented in Table 3. All structures, except PNIOCO, are unsymmetrically distorted. For PNIOCO the order of trigonal components is the same as reported ${ }^{38}$ for the $\mathrm{NaMg}$ salt, but different from that calculated for the average crystal structure with $C_{3}$ symmetry.

In certain cases the reduction of symmetry affects the calculations so that the expected degeneracies of the energy levels are removed and the eigenvectors appear to be composed of mixtures of functions transforming as $A$ and $E$. Notwithstanding this uncertainty, it is evident that the order of trigonal components is sensitive to small structural deformations of the coordination octahedron in $\left[\mathrm{Co}(\mathrm{ox})_{3}\right]$ complexes. In order to circumvent the problem of symmetry assignment of the calculated eigenvectors, we have fitted each crystal structure to a model of $C_{3}$ symmetry. The results (Table 4) again show that the order of trigonal components is sensitive to the structural variations which remain after $C_{3}$ averaging. Furthermore, comparison of the results in the cases of structures DAZVUV and QQQCMA, shows that the results are sensitive to lowering of symmetry as well.

The structure PNIOCO is different from the other four not only with respect to the symmetry but also with respect to the shape of the chelate rings. The angle $\alpha$ in PNIOCO is the smallest $\left[84.3^{\circ}\right.$ as compared to $86.50(33)^{\circ}$ for the other four structures] and the chelate ring puckering is the highest (the torsional angle $\mathrm{O}-\mathrm{C}-\mathrm{C}-\mathrm{O}$ is $24.0^{\circ}$ as compared to $8.8^{\circ}$ in average for DAZWEG, and $1.2^{\circ}$ in average for the other structures).

Qualitatively different results are obtained for PNIOCO if the chelate rings in this structure are made planar. Therefore, we argue that the chelate ring puckering (in addition to the overall deformations of the coordination octahedron) are affecting the calculated energy levels. In order to estimate the effect of chelate ring puckering we have studied two idealized modes of ring deformations : envelope and skew-boat puckering (see Fig. 5).

In the envelope puckering, torsional angles around $\mathrm{M}-\mathrm{O}$ bonds become different from zero

Table 4. Results of ligand field analysis ${ }^{a}$ on $\left[\mathrm{Co}(\mathrm{ox})_{3}\right]$ complexes derived from crystal structures ${ }^{b}$ by imposing $C_{3}$ symmetry

\begin{tabular}{ccccccc}
\hline Level & PNIOCO & PNIOCO $^{c}$ & QQQCMAa & QQQCMAb & DAZWEG & DAZVUV \\
\hline${ }^{1} T_{1 g}$ & $16,190 E_{\mathrm{a}}$ & $16,190 A_{2}$ & $16,280 A_{2}$ & $16,280 A_{2}$ & $16,300 A_{2}$ & $16,360 A_{2}$ \\
& $16,590 A_{2}$ & $16,410 E_{\mathrm{a}}$ & $16,500 E_{\mathrm{a}}$ & $16,500 E_{\mathrm{a}}$ & $16,500 E_{\mathrm{a}}$ & $16,490 E_{\mathrm{a}}$ \\
${ }^{1} T_{2 g}$ & $23,350 E_{\mathrm{b}}$ & $23,530 E_{\mathrm{b}}$ & $23,755^{d}$ & $23,740 A_{1}$ & $23,750 E_{\mathrm{b}}$ & $23,680 E_{\mathrm{b}}$ \\
& $24,280 A_{1}$ & $23,900 A_{1}$ & & $23,760 E_{\mathrm{b}}$ & $23,770 A_{1}$ & $23,940 A_{1}$ \\
\hline
\end{tabular}

${ }^{a}$ Best-fit parameter set from Table 2.

${ }^{b}$ See Table 1.

${ }^{c}$ Chelate rings forced to planar conformation.

${ }^{d}$ Accidental degeneracy. 

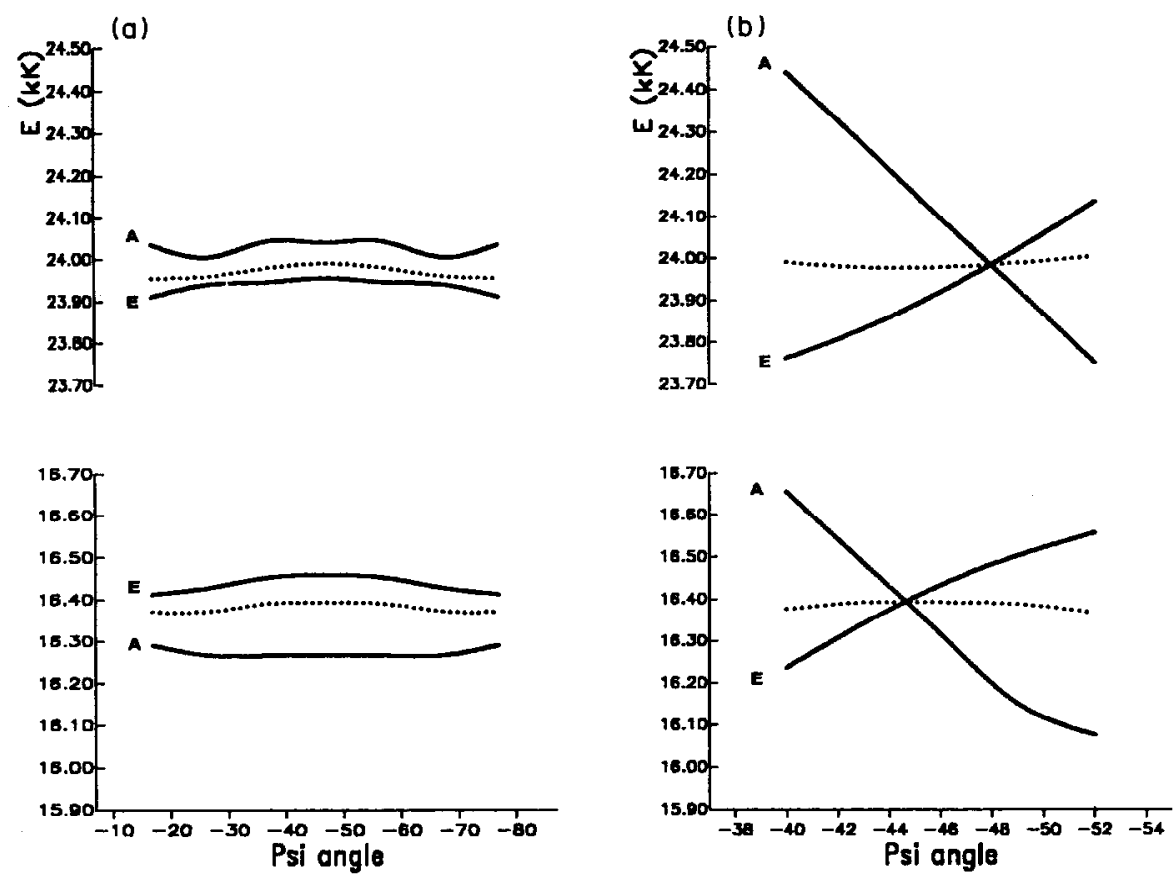

Fig. 5. The influence of the chelate ring conformation on the positions and splittings of singlets transitions. (a) Envelope type of ring puckering with $\psi$ angles of the opposite sign. (b) Skew-boat type of ring puckering with $\psi$ angles of the same sign. Baricentres are shown as dotted lines. For both diagrams the best-fit parameter set was used: $F_{2}=1123 \mathrm{~cm}^{-1}, F_{4}=108 \mathrm{~cm}^{-1}, \zeta=600 \mathrm{~cm}^{-1}$, $\alpha($ Trees $)=11 \mathrm{~cm}^{-1}, e(\sigma)=7400 \mathrm{~cm}^{-1}$ and $e(\pi \mathrm{c})=1700 \mathrm{~cm}^{-1}$.

and opposite in sign, whereas the value for the $\mathrm{O}-\mathrm{C}-\mathrm{C}-\mathrm{O}$ torsion remains close to zero. This puckering mode does not change the order of trigonal components and has a very small influence on the calculated energies (Fig. 5). On the other hand, the skew-boat puckering, characterized by substantial departure from planarity in the $\mathrm{O}-\mathrm{C}-\mathrm{C}-\mathrm{O}$ fragment and small torsional angles around $\mathrm{M}-\mathrm{O}$ bonds of the same sign, greatly influences the trigonal splitting and the order of trigonal components (Fig. 5). The skew-boat mode of puckering, present in PNIOCO, explains therefore, the difference between the results obtained with the strict crystal structure and the one corresponding to the planar rings. Furthermore, in the latter case, the results are qualitatively similar to those for the other crystal structures. Angle $\theta$ is closest to its octahedral value in one of the structures of QQQCMA (column 3 in Table 4). There the order of trigonal components of the "second" band is $A_{1}<E_{\mathrm{b}}$ as expected from Fig. 4 for the case $\alpha<90^{\circ}$. In all other crystal structures the variation in $\theta$ is more pronounced and the opposite order, $E_{\mathrm{b}}<A_{1}$, is obtained. The other of the two structures of QQQCMA (column 2 in Table 4) shows deformations both in $\theta$ and in $\omega$ in such a way that their effect is compensated and practically no splitting of ${ }^{1} T_{2 g}$ is obtained.

\section{CONCLUSIONS}

The results of AOM analysis on idealized $\left(D_{3}\right)$ geometries are shown to differ appreciably from those obtained on the basis of the real geometries. This raises the question of necessity to use real geometries in AOM calculations, or at least to consider the effects of possible structural deformations when analysing spectral data for systems which are not fully characterized in terms of their structures.

Furthermore, it was shown that chelate ring conformation is an important structural feature in ligand field studies. In [Co(ox $\left.)_{3}\right]$ structures, it is manifested in terms of deviations of oxalato metal chelate rings from planarity. They influence AOM results through the chainges in $\alpha, \theta$ and $\omega$ angles, as well as in the torsional angles around metal-ligand bonds.

Finally, it was shown that the AOM parameter may be treated as transferable across the series of chromophores $\mathrm{CoN}_{6-3 n} \mathrm{O}_{3 n}, n=0,1,2$. The $e_{c \varsigma \lambda}$ parameters for nitrogen were successfully taken over from $\left[\mathrm{Co}\left(\mathrm{NH}_{3}\right)_{6}\right]^{3+}$ to $\left[\mathrm{Co}(\mathrm{Gly} / \beta \text {-Ala })_{3}\right]$, and those for oxygen from $\left[\mathrm{Co}(\mathrm{Gly} / \beta-\mathrm{Ala})_{3}\right]$ to $\left[\mathrm{Co}(\mathrm{ox})_{3}\right]^{3-}$. The electron repulsion parameters optimized with such a choice for $e_{\xi \lambda}$ parameters yielded reasonable numerical values, which were within the limits for $\mathrm{CoN}_{6}$ and $\mathrm{CoO}_{6}$ chromo- 
phores. However, they do not fit the interpolated values, i.e. the "rule of average environment" is not applicable to electron repulsion parameters.

Acknowledgements-This work was supported by the Serbian Research Fund. Computer resources were generously made available by the Serbian State Institute of Statistics (RZS) through the Computer Laboratory of the University of Belgrade.

\section{REFERENCES}

1. W. Urland and S. R. Niketić, Chem. Phys. Lett. $1986,129,592$.

2. S. R. Niketić and W. Urland, Polyhedron 1987, 6, 947.

3. Parts of this work werc described in : (a) S. Zarić and S. R. Niketić, p. 165. First Yugoslav Conference on Molecular Sciences, Zagreb, Yugoslavia (May 1986). (b) S. Zarić, N. Mutić and S. R. Niketić, paper O24, p. 588. Sixth Yugoslav-Italian Crystallographic Conference, Pula, Yugoslavia (May 1989). (c) S. Zarić, M.Sc. Thesis, University of Belgrade, Yugoslavia (1990).

4. C. E. Schaffer and C. K. Jorgensen, Math. Sys. Medd. Dan. Vid. Selsk 1965, 34, 13.

5. C. E. Schaffer, Struct. Bond. 1968, 5, 68.

6. C. E. Schaffer, Pure Appl. Chem. 1970, 24, 361.

7. C. E. Schaffer, Struct. Bond. 1973, 14, 69.

8. S. Zarić and S. R. Niketić, Polyhedron 1991, 10, 2673.

9. A. Avdeev and J. P. Fackler Jr., Inorg. Chem. 1975, 14, 2002.

10. K. R. Dymrock and G. J. Palenik, Inorg. Chem. 1975, 14, 1220.

11. M. A. Flandera and E. C. Lingafelter, Inorg. Chem. $1976,15,750$.

12. D. L. Kepert, Inorg. Chem. 1972, 11, 1561.

13. D. L. Kepert, Progr. Inorg. Chem. 1977, 23, 1.

14. E. Larsen and G. N. La Mar, J. Chem. Educ. 1974, $51,633$.

15. K. N. Raymond, S. S. Isled, L. D. Brown, F. R. Franczek and J. H. Nibert, J. Am. Chem. Soc. 1976, 95, 1767.

16. E. I. Stiefel and G. F. Brown, Inorg. Chem. 1972, 11, 434.

17. Cambridge Structural Database. For description see, e.g. (a) F. H. Allen, S. Bellard, M. D. Brice, B. A.
Cartwright, A. Doubleday, H. Higgs, T. Hummelnik, B. G. Hummelnik-Peters, O. Kennard, W. D. S. Motherwell, J. R. Rogers and D. G. Watson, Acta Cryst. 1973, B35, 2331 ; (b) F. H. Allen, O. Kennard and R. Taylor, Accts Chem. Res. 1983, 16, 146.

18. S. Zarić and S. R. Niketic, to be submitted.

19. L. H. Pignolet, Top. Curr. Chem. 1975, 56, 91.

20. B. G. Thomas, M. L. Morris and R. L. Hilderbrandt, Inorg. Chem. 1978, 17, 2901.

21. J. Ferguson and D. L. Wood, Austral. J. Chem. 1970, 23, 861.

22. P. E. Hoggard, Coord. Chem. Rev. 1986, 70, 85.

23. P. E. Hoggard and K.-W. Lee, Inorg. Chem. 1988, 27, 2335.

24. M. Gerloch and R. C. Slade, Ligand Field Parameters. Cambridge University Press, Cambridge (1973).

25. R. E. Trees, Phys. Rev. 1951, 83, 756.

26. R. E. Trees, Phys. Rev. 1951, 84, 1089.

27. R. E. Trees, Phys. Rev. 1952, 85, 382.

28. C. K. Jorgensen, Modern Aspects of Ligand Field Theory. Elsevier/North-Holland, Amsterdam (1971).

29. N. D. Fenton and M. Gerloch, Inorg. Chem. 1987, 26, 3273.

30. K.-W. Lee and P. E. Hoggard, Inorg. Chem. 1988, 27, 907.

31. M. Kibler, G. Grenet and R. Chatterjee, J. Luminesc. 1979, 18/19, 609.

32. P. J. Steenkamp and J. W. Gonsalves, Austral. J. Chem. 1980, 33, 1705.

33. M. Kibler, Austral. J. Chem. 1982, 35, 231.

34. C. K. Jorgensen, Adv. Phys. Chem. 1963, 5, 33.

35. A. J. McCaffery, S. F. Mason and R. E. Ballard, $J$. Chem. Soc. 1965, 2883.

36. R. D. Gillard, D. J. Shepherd and D. A. Tarr, J. Chem. Soc., Dalton Trans. 1976, 594.

37. V. S. Sastri and C. H. Langford, Can. J. Chem. 1969, 47, 4237.

38. T. S. Piper and R. L. Carlin, J. Chem. Phys. 1961, 35, 1809.

39. R. Bramley, M. Brorson, A. M. Sargerson and C. E. Schaffer, J. Am. Chem. Soc. 1985, 107, 2780.

40. K. R. Butler and M. R. Snow, J. Chem. Soc. $(A)$ $1971,565$.

41. R. B. Wilson and E. I. Solomon, J. Am. Chem. Soc. $1980,102,4085$.

42. J. Ferguson, Prog. Inorg. Chem. 1970, 12, 159.

43. H. Okazaki, Y. Kushi and H. Yoneda, J. Am. Chem. Soc. 1985, 107, 4183. 